Originally published as:

Lempert, T., Neuhauser, $\mathrm{H}$.

Epidemiology of vertigo, migraine and vestibular migraine (2009) Journal of Neurology, 256 (3), pp. 333-338.

DOI: 10.1007/s00415-009-0149-2

The original publication is available at $\underline{h t t p: / / w w w . s p r i n g e r l i n k . c o m ~}$ 


\section{Epidemiology of vertigo, migraine and vestibular migraine}

Thomas Lempert, $\mathrm{MD}^{\mathrm{a}}$ and Hannelore Neuhauser, MD, $\mathrm{MPH}^{\mathrm{b}}$

${ }^{\text {a } D e p a r t m e n t ~ o f ~ N e u r o l o g y, ~ S c h l o s s p a r k-K l i n i k, ~ B e r l i n, ~ G e r m a n y ; ~ a n d ~ V e s t i b u l a r ~ R e s e a r c h ~}$ Group, Charité, Berlin, Germany

${ }^{\mathrm{b}}$ Robert Koch Institut, Department of Epidemiology, Berlin, Germany; and Vestibular Research Group, Charité, Berlin, Germany

Corresponding author for

proof and reprints:

Coauthor address:

Prof. Thomas Lempert

Dr. Hannelore Neuhauser

Neurologische Abteilung

Robert Koch Institut

Schlosspark-Klinik

General Pape Str. 62-66

Heubnerweg 2

12101 Berlin, Germany

14059 Berlin, Germany

Phone :0049 3045473462

Phone: 00493032641152

thomas.lempert@schlosspark-klinik.de

neuhauserh@rki.de 
Keywords: migraine, vestibular, vertigo, dizziness

\section{Abstract}

Both migraine and vertigo are common in the general population with lifetime prevalences of about $16 \%$ for migraine and $7 \%$ for vertigo. Therefore, a concurrence of the two conditions can be expected in about $1.1 \%$ percent of the general population by chance alone. However, recent epidemiological evidence suggests that the actual comorbidity is higher, namely $3.2 \%$. This can be explained by the fact that several dizziness and vertigo syndromes occur more frequently in migraineurs than in controls including benign paroxysmal positional vertigo, Meniere's disease, motion sickness, cerebellar disorders and anxiety syndromes which may present with dizziness. In addition, there is increasing recognition of a syndrome called vestibular migraine (VM), which is vertigo directly caused by migraine. VM affects more than $1 \%$ of the general population, about $10 \%$ of patients in dizziness clinics and at least $9 \%$ of patients in migraine clinics.

Clinically, VM presents with attacks of spontaneous or positional vertigo lasting seconds to days. Migrainous accompaniments such as headache, phonophobia, photophobia or auras are common but not mandatory. Cochlear symptoms may be associated but are mostly mild and non-progressive. During acute attacks one may find central spontaneous or positional nystagmus and, less commonly, unilateral vestibular hypofunction. In the symptom-free interval, vestibular testing adds little to the diagnosis as findings are mostly minor and non-specific. In the absence of controlled studies, treatment of VM is adopted from the migraine sphere comprising avoidance of triggers, stress management as well as pharmacotherapy for acute attacks and prophylaxis. 


\section{Introduction}

Recognition of an association between migraine and vertigo dates back almost 150 years when the English physician Edward Living noted that six out of 60 patients with migraine had spontaneous attacks of vertigo, as documented in his monograph On megrim: a contribution to the study of nerve storms $\left[{ }^{37}\right]$ That about $10 \%$ of migraineurs suffer from vertigo caused by migraine has been confirmed quite recently $\left[{ }^{41}\right]$ but the interrelations of migraine and vertigo are more complex. First of all, vertigo and migraine may coexist in the same individual by chance alone, as both are common conditions in the general population. Moreover, several vertigo syndromes have been shown to be epidemiologically associated with migraine: benign paroxysmal positional vertigo, Meniere's disease, motion sickness, cerebellar disorders and several psychiatric syndromes which may present with dizziness. Finally, there is vestibular migraine (VM), which is recurrent vertigo as a symptom of migraine.

\section{Epidemiology of migraine}

The epidemiology of migraine has been investigated by population-based studies in various countries on the basis of the International Classification of Headache Disorders $\left[{ }^{28}\right]$. Lifetime prevalences have been largely consistent across industrialized countries ranging from 13\% $\left[{ }^{11,36}\right]$ to $\left.16 \%{ }^{21,49}\right]$. Women were affected two to three times more often than men. The one year prevalence of migraine has been estimated at $11 \%$ according to a metaanalysis comprising numerous studies from around the world $\left[{ }^{55}\right]$.

\section{Epidemiology of vertigo}

Several studies have tried to assess the epidemiology of dizziness, which is a broad term, that includes vertigo and non-vestibular dizziness. Dizziness was found to be one of the most common complaints in medicine, affecting approximately $20 \%$ to $30 \%$ of the general population $\left[{ }^{32,63,25}\right]$. The epidemiology of vestibular vertigo was investigated only recently by 
means of a two stage approach $\left[{ }^{46}\right]$. The first step was a telephone screening of a representative general population sample (German National Health Interview Survey, $\mathrm{n}=4,869$ ) for moderate or severe dizziness or vertigo, followed by detailed validated neurotologic interviews ( $\mathrm{n}=1003)$. The lifetime prevalence of vertigo in adults aged 18-79 was $7 \%$, the one-year prevalence $4.9 \%$ and the one-year incidence $1.4 \%$. Interestingly, there was a marked female preponderance among individuals with vertigo (one year prevalence ratio male to female $1: 2.7)$. The study also showed that vertigo is recurrent in the vast majority of patients $(88 \%)$. Vertigo has a considerable individual and social impact, causing interruption of daily activities in $40 \%$ of affected individuals, sick leave in $41 \%$ and avoidance of leaving the house in $19 \%$ according to a recent survey $\left[{ }^{44}\right]$.

\section{Epidemiological association of migraine and vertigo}

An increased comorbidity of migraine and vertigo, which exceeds what random chance would predict, was identified in various selected patient groups and later confirmed on the population level. Notably there is no single study, that did not confirm such an association. Vertigo is two to three times more common in patients with migraine than in headache-free controls $\left[{ }^{33,59}\right]$ and in patients with tension-type headaches $\left[{ }^{31}\right]$. Vice versa, the prevalence of migraine has been shown to be elevated among patients with unclassified or idiopathic vertigo $[2,34,54]$. Similarly, migraine prevalence was 1.6 times higher in 200 consective patients from a dizziness clinic than in matched orthopedic controls $\left[{ }^{41}\right]$.

The lifetime prevalences of migraine (16\%) and vertigo (7\%) lead to an expected comorbidity of the two conditions in $1.1 \%$ of the general population. The actual comorbidity, however, as identified by the German National Health Survey, was $3.2 \%\left[{ }^{42}\right]$. A more recent populationbased study showed that individuals with migraine were much more likely to have vertigo and vertigo with accompanying headache (OR 3.8 and 8 respectively) than non-migraineurs after adjustment for age and $\operatorname{sex}\left[{ }^{45}\right]$. 


\section{Specific vertigo syndromes associated with migraine}

\section{Benign paroxysmal positional vertigo}

Benign paroxysmal positional vertigo (BPPV) is the most common vestibular disorder both in unselected patients $\left[{ }^{7}\right]$ and in migraineurs $\left[{ }^{41}\right]$ presenting to a dizziness clinic. Migraine is three times more common in patients with idiopathic BPPV than in patients with BPPV secondary to trauma or surgical procedures $\left[{ }^{29}\right]$. Moreover, migraine was two times more common in patients with idiopathic BPPV than in age and sex-matched controls $\left[{ }^{35}\right]$. Genetic factors and vascular damage to the labyrinth have been discussed as pathogenetic mechanisms linking the two conditions $\left[{ }^{29}\right]$.

\section{Menière’s disease}

An increased prevalence of migraine in patients with Menière's disease (MD) is well documented $\left[{ }^{51,50}\right]$. Migraine was twice as high in a group of 78 patients with unilateral or bilateral MD (based on the American Academy of Otolaryngology criteria), than in an ageand sex-matched control group (56\% vs. $\left.25 \%, \mathrm{p}<0.001){ }^{51}\right]$. Migraine leads to a greater susceptibility of developing MD, as suggested by a study in which MD patients had an earlier onset of symptoms and a greater frequency of bilateral hearing loss when they also had migraine $\left[{ }^{15}\right]$.

\section{Motion sickness}

Motion sickness is more prevalent in patients with migraine (30\% to $70 \%)$ than in headachefree controls or tension headaches $(20 \%$ to $\left.40 \%){ }^{19,31,33,38}\right]$. The association is more pronounced in children $\left[{ }^{6}\right]$ and in migraine with aura $\left[{ }^{33}\right]$ Migraineurs are also prone to "visual vertigo" induced by optokinetic stimuli $\left[{ }^{33,19}\right]$, which can be conceptualized as a decreased threshold for visual-vestibular interaction. 


\section{Cerebellar disorders}

Cerebellar dysfunction is linked in various ways to migraine $\left[{ }^{60}\right]$ but does not normally present with "true" vertigo. However, both patients with familial hemiplegic migraine and episodic ataxia type 2 may have symptoms of basilar-type migraine including headaches and vertigo attacks $\left[{ }^{24}\right]$ on the background of slowly progressive cerebellar dysfunction. The genetic basis of these disorders are mutations in the CACNA1A gene coding for the $\alpha_{1 \mathrm{~A}}$

subunit of a neuronal $\mathrm{Ca}^{2+}$ channel, which is heavily expressed in the cerebellum $\left[{ }^{17}\right]$. Cerebellar signs are usually not present in the common types of migraine, but some investigators found subclinical hypermetria and other subtle cerebellar signs in patients with migraine with, or without aura $\left[{ }^{53,27}\right]$.

\section{Psychiatric syndromes}

Dizziness, sometimes perceived as spinning vertigo, is the second most common symptom of panic attacks after palpitations $\left[{ }^{39}\right]$ and can be a symptom of major depression as well. There are bidirectional associations of migraine with both major depression and panic disorder, with migraine being a risk factor for first-onset major depression and panic disorder and vice versa. $\left[{ }^{10}, 12\right]$. 


\section{Vestibular migraine}

\section{Diagnostic criteria}

Vestibular migraine (synonyms: migrainous vertigo, migraine-associated dizziness, benign recurrent vertigo) designates vertigo attacks which are directly caused by migraine. The current International Classification of Headache Disorders (ICHD) of the International Headache Society does not include vertigo as a migrainous symptom in adults, except in the framework of basilar-type migraine (Internat. Classif). For a diagnosis of basilar-type migraine, the ICHD requires at least two posterior circulation manifestations lasting between 5 and 60 minutes, followed by a migraine headache. Less than $10 \%$ of patients with VM fulfill these criteria $\left[{ }^{14,30,18,41}\right]$ meaning that most adult patients with VM cannot be classified with the current criteria.

Like migraine itself VM is diagnosed on the basis of clinical information as there are no specific biological markers. A preliminary classification, using operational clinical criteria modeled on the ICHD, proposed two separate diagnostic categories: definite VM and the more sensitive but less specific, probable VM $\left[{ }^{41}\right]$ (Table 1).

\section{Epidemiology and demographic features of vestibular migraine}

According to these diagnostic criteria, the frequency of definite VM was 7\% in a group of 200 consecutive dizziness clinic patients, and $9 \%$ in a group of 200 migraine patients $\left[{ }^{41}\right]$. In a population-based study ( $\mathrm{n}=4869$ adults) with screening interviews followed by expert telephone interviews (German National Health Survey), the lifetime prevalence of definite VM was estimated at $0.98 \%(95 \%$ CI $0.7-1.37)\left[{ }^{42}\right]$. Interestingly, this is considerably less than the $3.2 \%$ from the same sample who had both migraine and vertigo, partly because probable VM was not included and partly because patients with migraine may suffer from other vestibular disorders (see above). This emphasizes the necessity of a thorough 
neurotological evaluation of all patients with migraine and vertigo before making a diagnosis of VM.

VM may occur at any age $\left[{ }^{16,14,30}\right]$ with a reported female to male ratio between 1.5 and 5 to $1\left[{ }^{14,30,18,41}\right]$. Familial occurrence is not uncommon, probably based on an autosomal dominant pattern of inheritance with decreased penetrance in men $\left[{ }^{47}\right]$. In most patients, migraine headaches begin earlier in life than VM $\left[{ }^{18,41}\right]$. Some patients are headache-free for years before VM manifests itself $\left[{ }^{18}\right]$. Benign paroxysmal vertigo of childhood is probably an early manifestation of VM and affects about $2.8 \%$ of unselected children between the ages of 6 and 12 years $\left[{ }^{1}\right]$.

\section{Clinical features}

The clinical characteristics of VM have been elucidated by several large case series from specialized dizziness clinics $\left[{ }^{14,16,18,26,30,31,41}\right]$. Patients with VM present with spontaneous or positional vertigo. Some experience a sequence of spontaneous vertigo transforming into positional vertigo later in the attack $\left[{ }^{40,56}\right]$. Altogether, $40-70 \%$ of patients have positional vertigo (but not benign paroxysmal positional vertigo) in the course of the disease $\left.{ }^{31,26,56}\right]$. Head motion intolerance, íe imbalance, illusory motion and nausea aggravated or provoked by head movements, is a frequent additional symptom $\left[{ }^{14,30}\right]$. Visual vertigo, which is vertigo provoked by moving visual scenes [traffic, cinema] can be another prominent feature of VM $\left[{ }^{14,61}\right]$. Nausea and imbalance are frequent but unspecific accompaniments of acute VM. Both duration and frequency of attacks can vary between patients and in individual patients over time. The duration of vertigo ranges from seconds (about 10\%) and minutes $(30 \%)$ to hours $(30 \%)$ and several days $\left.(30 \%){ }^{[16,30,31,18,58}\right]$ For some patients, it may take weeks to fully recover from an attack. The attacks may occur days, months or even years apart in an irregular fashion. Overall, between $10 \%$ and $30 \%$ of patients have vertigo with the typical duration of a migraine aura, i.e. 5 to 60 minutes $\left[{ }^{18,41}\right]$. VM often misses not only the 
duration criterion for an aura as defined by the IHS, but also the temporal relationship to migraine headaches: vertigo can precede headache as would be typical for an aura, may begin with headache or appear late in the headache phase. Many patients experience both attacks with and without headache and in some, vertigo and headache never occur together $\left[{ }^{16,41,30}\right]$. Photophobia, phonophobia, osmophobia and visual or other auras are common accompaniments of VM. These phenomena are of diagnostic importance, since they may represent the only apparent link between vertigo and migraine. Hearing loss and tinnitus are not prominent symptoms of VM but have been reported in individual patients with VM $\left[{ }^{14,30,31,48}\right]$. Hearing loss is usually mild and transient, without progression in the course of the disorder which discriminates VM from Meniere's disease $\left[{ }^{30}\right]$.

Precipitants of attacks may serve as diagnostic clues: menstruation, deficient or irregular sleep, excessive stress, relief from stress (weekends, beginning of a holiday), specific foods such as matured cheese, red wine and glutamate and finally sensory stimuli such as bright or scintillating lights, intense smells or noise. The triggers are highly individual and each one applies only for a few percent of the migraine population.

Psychiatric comorbidity, particularly with anxiety disorders, reaches $65 \%$ in VM as compared to only $22 \%$ in BPPV $\left[{ }^{20}\right]$. In an individual patient, both vestibular and psychiatric mechanisms may contribute to the dizziness $\left[{ }^{22}\right]$. These factors need to be weighed carefully to direct treatment appropriately.

\section{Findings on examination}

The general neurologic, vestibular and otologic examination is usually normal in the symptom-free period $\left[{ }^{16}\right]$. About $10-20 \%$ of VM patients have unilateral hypoexcitability to caloric stimulation $\left[{ }^{16}\right]$. Neuro-ophthalmological evaluation may reveal mild central oculomotor deficits in the absence of other brainstem or cerebellar signs $\left[{ }^{18}\right]$. During the acute phase of VM patients often have imbalance and central vestibular findings such as 
spontaneous downbeating, upbeating or pure torsional nystagmus and/or persistent positional nystagmus $\left[{ }^{56,57}\right]$. Some have a transient unilateral peripheral hypofunction with spontaneous horizontal nystagmus and an abnormal head thrust test $\left[{ }^{57}\right]$. The pathophysiology of VM is unknown. Various hypotheses have been proposed but, so far, none has had any impact on the management of these patients $\left[{ }^{23}\right]$.

\section{Treatment}

When attacks of VM attacks are severe and frequent, acute or prophylactic treatment is warranted. However, apart from one small and inconclusive study on the use of zolmitriptan for acute $\mathrm{VM}\left[{ }^{43}\right]$ current treatment recommendations are based on expert opinion rather than randomized placebo-controlled trials. A few case reports suggest that drugs used for migraine prophylaxis may be effective. These include propranolol $\left[{ }^{26}\right]$ metoprolol $\left[{ }^{18}\right]$, tricyclic antidepressants $\left[{ }^{52}\right]$, pizotifen $\left[{ }^{52,61}\right]$, topiramate $\left[{ }^{13}\right]$ and flunarizine $\left[{ }^{18}\right]$. Lamotrigine $\left[{ }^{9}\right]$ and the carbonic anhydrase-inhibitors acetazolamide $\left[{ }^{4}\right]$ and dichlorphenamid $\left[{ }^{3}\right]$ which are not ordinarily used for migraine prophylaxis, have also been tried successfully, but these studies were not randomized or controlled.

Treatment of acute VM with acute migraine medication can be attempted with triptans

$\left[{ }^{43}\right]$ and vestibular suppressants such as promethazine, dimenhydrinate, and meclizine $\left[{ }^{5}\right]$. A retrospective study found that the effect of triptans on vertigo correlated with its effect on headache $\left[{ }^{8}\right]$. Non-pharmaceutical approaches may be more efficacious than drugs in individual patients. A thorough explanation of the migrainous origin of the attacks may relieve unnecessary fears.Avoidance of identified triggers, stress management and vestibular rehabilitation $\left[{ }^{62}\right]$ can be helpful. 


\section{References}

1. Abu-Arafeh I, Russell G (1995) Paroxysmal vertigo as a migraine equivalent in children: a population-based study. Cephalalgia 15:22-25

2. Aragones JM, Fortes-Rego J, Fuste J, Cardozo C (1993) Migraine: An alternative in the diagnosis of unclassified vertigo. Headache 33:125-8

3. Asprella Libonati G, Gagliardi G (2004) La malattia di Meniere e vertigine emicranica: terapia intercritica, terapia medica. Otoneurologia 18:40-42

4. Baloh RW, Foster CA, Yue Q, Nelson SF.(1996) Familial migraine with vertigo and essential tremor. Neurology 46:458-460

5. Baloh RW (1997) Neurotology of migraine. Headache 37: 615-621

6. Barabas G, Matthews WS, Ferrari M. (1983) Childhood migraine and motion sickness. Pediatrics 72: 188-190

7. Bath AP, Walsh RM, Ranalli PT, Tyndel F, Bance M, Mai R, Rutka JA (2000) Experience from a multidisciplinary „dizzy“ clinic. Am J Otol 21:92-97

8. Bikhazi P, Jackson C, Ruckenstein MJ (1997) Efficacy of antimigrainous therapy in the treatment of migraine-associated dizziness. Am J Otol 18:350-354 
9. Bisdorff AR (2004) Treatment of migraine related vertigo with lamotrigine an observational study. Bull Soc Sci Med Grand Duche Luxemb 2:103-8

10. Breslau N, Schultz LR, Stewart WF, Lipton RB, Lucia VC, Welch KM (2000) Headache and major depression: is the association specific to migraine? Neurology 54:308-313

11. Breslau N, Davis GC, Andreski P (1991) Migraine, psychiatric disorders, and suicide attempts: an epidemiologic study of young adults. Psychiatry Res 37:11-23

12. Breslau N, Schultz LR, Stewart WF, Lipton R, Welch KMA (2001) Headache types and panic disorder. Directionality and specificity. Neurology 2001; 56:350-354

13. Carmona S, Settecase N (2005) Use of topiramate (topamax) in a subgroup of migrainevertigo patients with auditory symptoms. Ann N Y Acad Sci 1039:517-20

14. Cass SP, Ankerstjerne JKP, Yetiser S, Furman J, Balaban C, Aydogan B (1997) Migrainerelated vestibulopathy. Ann Otol Rhinol Laryngol 106:182-189

15. Cha YH, Brodsky J, Ishiyama G, Sabbatti C, Baloh RW (2007) The relevance of migraine in patients with Menière's disease. Acta Oto-Laryngologica 127:1241-1245

16. Cutrer FM, BalohRW (1992) Migraine-associated dizziness. Headache 32: 300-304 
17. Denier C, Ducros A, Vahedi K, Joutel A, Thierry P, Ritz A et al. (1999) High prevalence of CACNA1A truncations and broader clinical spectrum in episodic ataxia type 2. Neurology 52: 1816-1821

18. Dieterich M, Brandt T (1999) Episodic vertigo related to migraine (90 cases): vestibular migraine? J Neurol 246: 883-892

19. Drummond PD (2005) Triggers of motion sickness in migraine sufferers. Headache $45: 653-656$

20. Eckhardt-Henn A, Best C, Bense S, Breuer P, Diener G, Tschan R et al. (2008) Psychiatric comorbidity in different organic vertigo syndromes. J Neurol 255:420-428

21. Edmeads J, Findlay H, Tugwell P (1993) Impact of migraine and tension-type headache on life style, consulting behaviour, and medication use: a Canadian population survey. Can J Neurol Sci 20:131-137

22. Furman JM, Balaban CD, Jacob RG, Marcus DA (2005) Migraine-anxiety related dizziness (MARD): a new disorder? J Neurol Neurosurg Psychiat 76:1-8

23. Furman JM, Marcus DA, Balaban CD (2003) Migrainous vertigo: development of a pathogenetic model and structured diagnostic interview. Curr Opin Neurol 16:5-13

24. Haan J, Terwindt GM, Ophoff RA, Bos PL, Frants RR, Ferrari MD Krommenhoek T, Lindhout DL, Sandkuyl LA, Van Eyk R (1995) Is familial hemiplegic migraine a hereditary form of basilar migraine? Cephalalgia 15:477-81 
25. Hannaford PC, Simpson JA, Bisset AF, Davis A, McKerrow W, Mills R (2005) The prevalence of ear, nose and throat problems in the community: results from a national cross-sectional postal survey in Scotland. Fam Pract 22:227-233

26. Harker LA, Rassekh C (1988) Migraine equivalent as a cause of episodic vertigo. Laryngoscope 98:160-164.

27. Harno H, Hirvonen T, Kaunisto MA, Aalto H, Levo H, Isotalo E, et al. (2003) Subclinical vestibulocerebellar dysfunction in migraine with and without aura. Neurology 61:17481752

28. International Headache Society Classification Subcommittee (2004) International classification of headache disorders. 2nd edition. Cephalalgia 24 Suppl 1: 1-160

29. Ishiyama A, Jacobson KM, Baloh RW (2000) Migraine and benign positional vertigo. Ann Otol Rhinol Laryngol 109:377-380

30. Johnson GD (1998) Medical management of migraine-related dizziness and vertigo. Laryngoscope 108: 1-28

31. Kayan A, Hood JD (1984) Neuro-otological manifestations of migraine. Brain 107:11231142 
32. Kroenke K, Price RK (1993) Symptoms in the community. Prevalence, classification, and psychiatric comorbidity. Arch Intern Med 153:2474-2480

33. Kuritzky A, Ziegler DK, Hassanein R (1981) Vertigo, motion sickness and migraine. Headache 21:227-231

34. Lee H, Sohn SI, Jung DK, Cho YW, Lim JG, Yi SD (2002) Migraine and solated recurrent vertigo of unknown cause. Neurol Res 24: 664-665

35. Lempert T, Leopold M, von Brevern M, Neuhauser H (2000) Migraine and benign positional vertigo. Ann Otol Rhinol Laryngol 109:1176

36. Lipton RB, Stewart WF, Diamond S, Diamond ML, Reed M (2001) Prevalence and burden of migraine in the United States: data from the American Migraine Study II. Headache 41:646-657

37. Liveing E (1873) On megrim, sick headache and some allied health disorders: a contribution to the pathology of nerve storms. London: Churchill: 129-48

38. Marcus DA, Furman JM, Balaban CD (2005) Motion sickness in migraine sufferers. Expert Opin Pharmacother 6:2691-2697

39. Margraf J, Taylor B, Ehlers A, Roth WT, Agras WS (1987) Panic attacks in the natural environment. J Nerv Ment Dis 175:558-565. 
40. Moretti G, Manzoni GC, Caffara P, Parma M (1980) „Benign recurrent vertigo“ and its connection with migraine. Headache 20:344-346

41. Neuhauser H, Leopold M, von Brevern M, Arnold G, Lempert T (2001) The interrelations of migraine, vertigo, and migrainous vertigo. Neurology 56:436-441

42. Neuhauser HK, Radtke A, von Brevern M, Feldmann M, Lezius F, Ziese T, Lempert T (2006) Migrainous vertigo: prevalence and impact on quality of life. Neurology 67:1028-1033

43. Neuhauser H., Radtke A, von Brevern M, Lempert T (2003) Zolmitriptan for treatment of migrainous vertigo: a pilot randomized placebo-controlled trial. Neurology 60: 882-883

44. Neuhauser H, Radtke A, von Brevern M, Lezius F, Feldmann M, Lempert T (2008) Burden of dizziness and vertigo in the community. Arch Int Med 168: 2118-2124

45. Neuhauser H, von Brevern M, Radtke A, Lempert T (2008) Population-based epidemiological evidence for the link between dizziness and migraine (Abstract). $25^{\text {th }}$ Barany Society Meeting, Kyoto: 177

46. Neuhauser H, von Brevern M, Radtke A, Lezius F, Feldmann M, Ziese T, Lempert T (2005) Epidemiology of vestibular vertigo: a neurotological survey of the general population. Neurology 65:898-904

47. Oh AK, Lee H et al. (2001) Familial benign recurrent vertigo. Am J Med Genet 100: 287291 
48. Parker W (1991) Migraine and the vestibular system in adults. Am J Otol 12:25-34

49. Rasmussen BK, Jensen R, Schroll M, Olesen J (1991) Epidemiology of headache in a general population - a prevalence study. J Clin Epidemiol 44:1147-1157

50. Rassekh CH, Harker LA (1992) The prevalence of migraine in Meniere's disease. Laryngoscope 102: 135-138

51. Radtke A, Lempert T, Gresty MA, Brookes GB, Bronstein AM, Neuhauser A (2002) Migraine and Meniere's disease: is there a link? Neurology 59: 1700-1704

52. Reploeg MD, Goebel JA (2002) Migraine-associated dizziness: patient characteristics and management options. Otol Neurotol 23: 364-371

53. Sandor PS, Mascia A, Seidel L, de Pasqua V, Schoenen J (2001) Subclinical cerebellar impairment in the common types of migraine: a three-dimensional analysis of reaching movements. Ann Neurol 49: 668-672

54. Savundra PA, Carroll JD, Davies RA, Luxon LM (1997) Migraine-associated vertigo. Cephalalgia 17:505-510

55. Stovner LJ, Hagen K, Jensen R, Katsavara Z, Lipton R, Scher A, Steiner T, Zwart JA (2007) The global burden of headache: a documentation of headache prevalence and disability worldwide. Cephalalgia 27:193-210 
56. von Brevern M, Radtke A, Clarke AH, Lempert T (2004) Migrainous vertigo presenting as episodic positional vertigo. Neurology 62:469-472

57. von Brevern M, Zeise D, Neuhauser H, Clarke A, Lempert T (2005) Acute migrainous vertigo: clinical and oculographic findings. Brain 128: 365-374

58. Versino M, Sances G, Anghileri E, Colnaghi S, Albizzati C, Bono G, Cosi V (2003) Dizziness and migraine: a causal relationship? Funct Neurol 18:97-101

59. Vuković V, Plavec D, Galinović I, Lovrencić-Huzjan A, Budisić M, Demarin V (2007) Prevalence of vertigo, dizziness, and migrainous vertigo in patients with migraine. Headache 47:1427-1435

60. Vincent M, Hadjikhani N (2007). The cerebellum and migraine. Headache 47:820-833

61. Waterston J (2004) Chronic migrainous vertigo. J Clin Neurosci 11: 384-388

62. Whitney SL, Wrisley DM, Brown KE, Furman JM (2000) Physical therapy for migrainerelated vestibulopathy and vestibular dysfunction with history of migraine. Laryngoscope $110: 1528-1534$

63. Yardley L, Owen N, Nazareth I, Luxon L (1998) Prevalence and presentation of dizziness in a general practice community sample of working age people. Br J Gen Pract 48:11311135 
Table 1. Diagnostic criteria for vestibular migraine [41]

\section{Definite vestibular migraine}

A. Episodic vestibular symptoms of at least moderate severity

B. Current or previous history of migraine according to the 2004 criteria of the International Headache Society

C. One of the following migrainous symptoms during $\geq 2$ attacks of vertigo:

migrainous headache, photophobia, phonophobia, visual or other auras

D. Other causes ruled out by appropriate investigations

\section{Comment:}

Vestibular symptoms are rotational vertigo or another illusory self or object motion. They may be spontaneous or positional. Vestibular symptoms are "moderate" if they interfere with but do not prohibit daily activities and "severe" if patients cannot continue daily activities.

\section{Probable vestibular migraine}

A. Episodic vestibular symptoms of at least moderate severity

B. One of the following:

a) Current or previous history of migraine according to the 2004 criteria of the IHS

b) Migrainous symptoms during vestibular symptoms

c) Migraine-precipitants of vertigo in more than $50 \%$ of attacks: food triggers, sleep irregularities, hormonal change

d) Response to migraine medications in more than $50 \%$ of attacks

C. Other causes ruled out by appropriate investigations 